\title{
aniki
}

Revista Portuguesa da Imagem em Movimento

Portuguese Journal of the Moving Image

\section{Som e Fúria no Cinema Brasileiro: Cultura e política desde Pernambuco}

\author{
Márcia Vanessa Malcher dos Santos \\ Universidade Estadual de Maringá \\ marciamalcher9@gmail.com \\ https://orcid.org/oooo-0003-2872-7247
}

RESUMO Este ensaio busca evidenciar as disposições políticas do cinema de Kleber Mendonça Filho a partir de seus três longas-metragens de ficção, $O$ som ao redor (2012), Aquarius (2016) e Bacurau (2019), de maneira a apontar a qualidade dos encontros e desencontros de sua obra com a realidade socio-histórica brasileira, especialmente na última década, período marcado pelos protestos massivos de 2013, pela deposição da presidenta Dilma Rousseff (2016) e pela eleição de Jair Bolsonaro (2018). Para tanto, situa Kleber Mendonça como parte da cena contemporânea de cinema de Pernambuco e propõe uma abordagem analítica que articula fatores estéticos e extraestéticos de modo simultâneo. Conclui que essa tríade fílmica, ainda que constituída por formas de prática paradoxais, é uma importante contribuição para pensar o Brasil, a sua história recente e a relação existente entre cultura, política e sociedade.

Pala vras-Ch A Ve Cinema; cultura; política; Pernambuco; Kleber Mendonça Filho.

\section{Introdução}

A intensidade com que os três longas-metragens de ficção de Kleber Mendonça Filho foram ou estiveram relacionados à recente realidade social e política brasileira envolveu um emaranhado composto por diferentes atores, em especial os críticos, os espectadores, a equipe e o próprio diretor. Alguns fatos suscitados ou gerados pelos filmes na ocasião dos seus respetivos lançamentos denotam essa complexa articulação. O primeiro deles, $O$ som ao redor (2012), ainda que lançado de forma modesta, gerou repercussão após ser incluído na lista dos melhores filmes do ano pelo crítico A.O. Scott, do The New York Times 
(Folha de S. Paulo, 2012), ao que se seguiu uma série de prêmios em festivais nacionais e internacionais. ${ }^{1}$ Mas essa visibilidade também suscitou uma polêmica entre o cineasta e o então diretor executivo da Globo Filmes, Carlos Eduardo Rodrigues, deflagrada após a crítica de Kleber Mendonça Filho à empresa: "Minha tese é a seguinte: se meu vizinho lançar o vídeo do churrasco dele no esquema Globo Filmes, ele fará 200 mil espectadores no primeiro final de semana” (Mena 2013). O diretor se contrapunha assim à conceção de que bilheteria é sinónimo de qualidade artística, afirmando ainda que a coprodutora "atrofia o conceito de diversidade no cinema brasileiro e adestra um público cada vez mais dopado para reagir a um cinema institucional e morto" (Araújo 2013). Dentre um grande volume de análises e comentários feitos sobre o filme, destacam-se duas considerações de Jean-Claude Bernardet, um dos críticos mais reputados do cinema brasileiro. Bernardet afirmou que com o novo cinema pernambucano, a luta de classes havia voltado ao cinema brasileiro e também questionou: "o que está se fazendo no Recife é cinema político? É cinema político por causa de sua temática? [...] É político um cinema que não tem público?” (Pinto 2012).

O ano de lançamento do segundo filme, Aquarius (2016), por sua vez, coincidiu com o processo institucional, encampado como impeachment e denunciado enquanto golpe por diversas frações da sociedade, que destituiu a presidenta eleita Dilma Rousseff. ${ }^{2}$ Em protesto, a equipe do longa empunhou cartazes no tapete vermelho do Festival de Cannes, nos quais se lia: "Brazil is experiencing a Coup d'Etat", "un coup d'Ètat a eu lieu au Brésil", "54.501.118 votes set on fire!" ${ }^{3}$ Ademais, ao desembarcar nas salas de cinema brasileiras, em inúmeras sessões foi possível presenciar manifestações pelo "Fora Temer!”, direcionadas ao governo interino, liderado por Michel Temer, que assumiu a Presidência da República (2016-2018). Mas as relações entre o filme e a

\footnotetext{
${ }^{1}$ Entre eles, o Prêmio Itamaraty de melhor filme na Mostra Internacional de Cinema de São Paulo (2012); melhor filme e roteiro no Festival do Rio (2012); e o Prêmio da Federação Internacional de Críticos no Festival International de Roterdã (2012).

${ }^{2}$ Danilo Martuscelli (2020), ao refazer teoricamente o debate político e acadêmico que marcou essa conjuntura em torno da caracterização polissêmica se houve golpe ou impeachment, defende a terminologia "golpe jurídico-parlamentar" (a qual compartilhamos), propondo uma categorização que se distancia da abordagem institucionalista filiando-se à perspetiva de que os conflitos reprodutivos de classe condicionaram e atravessaram esse processo.

3 “Brasil está vivendo um golpe de Estado", "um golpe de estado está em curso no Brasil”, “54.501.118 votos sendo queimados!” (tradução nossa).
}

aniki Ensaios | Essays 
realidade política do país não se restringiram ao ato da equipe, nem às reações dos espectadores que compartilhavam a crítica ao golpe, pois também acionou as forças que o sustentaram. Alguns eventos consecutivos ao protesto na França expressaram isso: denúncia anónima que resultou em uma ação judicial incongruente movida contra o cineasta (Fernandes 2017); as idas e vindas do Ministério da Justiça em torno da mudança da classificação etária de Aquarius de 16 para 18 anos (Nogueira e Pessoa 2016); e suspeitas públicas, reforçadas por Kleber Mendonça, de falta de isenção dos membros responsáveis pela escolha do filme que representaria o Brasil na competição pelo Oscar daquele ano, após um deles, o crítico Marcos Petrucelli, se manifestar contrário ao ato de protesto em Cannes em sua página do Facebook, afirmando, "vergonha é o mínimo que se pode dizer" (Genestreti 2016; Jansen 2016).

Também Bacurau (2019), codirigido com Juliano Dornelles, esteve atrelado à oposição ao presidente recém-eleito Jair Bolsonaro desde a estreia. Após a exibição do filme no Festival de Cannes, do qual saiu com o Prêmio do Júri, Kleber Mendonça Filho afirmou: "Esse é um momento muito importante no nosso país. E esse é um filme sobre resistência, sobre educação e sobre ser brasileiro no mundo" (Marques s.d.). A intensa receção, por meio de críticas, reportagens e entrevistas, ou imprimiu ao filme um caráter predominantemente simbólico, vendo-o como um retrato do país que passou a ser governado pelas forças políticas revanchistas eleitas em 2018 (Bentes 2019, por exemplo), ou buscou enfatizar o seu teor alegórico, desvinculando-o, ao menos mais diretamente, da relação com a conjuntura política imediata (Musse 2019, por exemplo). Do primeiro caso, decorreram inúmeras correlações possíveis entre realidade e ficção abordando a catástrofe social, a violência e o autoritarismo crescentes, ao passo que as interpretações alegóricas buscaram enfatizar a autonomia da forma artística, às voltas com as significações da "ideia” de Brasil, a partir de diferentes ênfases: da perspetiva colonial, passando pela questão racial e étnica, até as desigualdades da formação histórica brasileira. O fato é que houve um consenso na perceção de Bacurau como um filme político posicionado no lugar oposto aos preceitos então reunidos na figura do presidente eleito Jair Bolsonaro. Não à toa, uma vez mais, ao final de muitas das sessões nos cinemas, foram ouvidas manifestações 
contrárias ao novo presidente e a palavra de ordem "Lula livre!", em defesa da libertação do ex-presidente, Luiz Inácio Lula da Silva, então preso pela Operação Lava Jato. ${ }^{4}$

Como expressa esse pequeno acervo de acontecimentos, estabelecer a relação entre cultura e política é um movimento arriscado já que essa interconexão revela (ou oculta) múltiplas camadas para além da superfície e toda uma história sedimentada. O debate sobre o papel social da arte e dos intelectuais é extenso e os seus vestígios, vez ou outra, são reativados. No Brasil, orbitou em torno de algumas polémicas centrais envolvendo o modernismo brasileiro nos anos 1920 e a geração literária comprometida dos anos 1930 (Miceli 1979); a divergência em torno da relação forma/conteúdo no interior da arte engajada nos anos 1950/1960 (Ridenti 2010); a relação com a Indústria Cultural que se consolidou no país (Ortiz 2006); o tropicalismo e suas leituras críticas (Napolitano e Villaça 1998); e, finalmente, a permanência ou não do seu teor político pós-redemocratização (Pellegrini 2008).

Ao longo desse percurso histórico, as relações estabelecidas com os diferentes governos foram marcadas por momentos de compartilhamento de uma agenda de princípios aberta a dissonâncias, pela tolerância ou intolerância recíproca, o que envolveu invariavelmente o aparato institucional do Estado, e pela oposição declarada em suas múltiplas facetas. Esse quadro nos traz à contemporaneidade que, em muitos aspetos, impele-nos a mudar as perguntas em vez de apontar respostas. Isso porque, como bem lembra Fredric Jameson em artigo recente, a realidade atual, ao instaurar a mercantilização máxima de todos os aspetos da vida cotidiana e decretar a redução da arte à forma mercadoria como algo definitivo, castiga os argumentos e posições teóricas abstratas, como a oposição entre formalismo e realismo. Por conta disso, "o que estaria em questão não é se a arte política é possível, mas se a arte mesma pode continuar a

\footnotetext{
${ }^{4}$ A Operação Lava Jato, um conjunto de investigações da Polícia Federal (PF) liderado pelo juiz Sergio Moro, condenou Luiz Inácio Lula da Silva por corrupção passiva e lavagem de dinheiro, mantendo-o sob cárcere do dia 7 de abril de 2018 a 8 de novembro de 2019. A prisão do ex-presidente retirou os seus direitos políticos, o que o impediu de participar como candidato do pleito eleitoral a Presidência da República de 2018. Lula foi libertado com base em uma decisão do Supremo Tribunal Federal, que, recentemente, também anulou os processos contra ele no âmbito da Lava Jato e declarou a parcialidade do juiz Sergio Moro no julgamento do caso (Angelo e Calegari 2021; Falcão e Vivas 2021).
} 
existir" (Jameson 2021) no atual grau de estetização do capitalismo tardio.

Se as versões modernistas organizadas pelas vanguardas, que foram as soluções mais satisfatórias de resistência à mercantilização - situadas na subversão e transgressão da forma, aliadas ao escândalo, revelação doentia ou exposição do conteúdo -, tiveram o seu acervo de estratégias institucionalizado pelo mercado da arte "contemporânea" e universidades, como afirma Jameson (2021), a arte política atual, ao mesmo tempo em que se insere de variadas formas em arranjos materiais aos quais o seu destino está atrelado, segue acompanhada desse perigo iminente. Muito provavelmente também segue assombrada pelo desafio de como estimular, em termos de forma e conteúdo, o reposicionamento dos sentidos diante da generalizada impressão de exaustão da representação, dado o excesso das imagens hegemónicas e a repetição frenética de seus signos. O desafio crucial da arte contemporânea que preserva a intervenção política parece ser a busca por formas capazes de transpor essa saturação. Formas, acreditase, que são a um só tempo estéticas e extraestéticas, daí a necessidade de interligá-las analiticamente para que se possa aferir da maneira mais acurada possível como dada criação responde objetiva, formal e politicamente (no sentido amplo mas também contextual) ao seu próprio tempo histórico.

A partir dessa diretriz metodológica, cuja delimitação será o ponto de partida deste ensaio, objetiva-se apresentar as formas de práticas do cineasta Kleber Mendonça Filho, primeiro, relacionando-o ao seu tempo-lugar de atuação, a cena de cinema de Pernambuco; depois apresentando as suas singularidades juntamente com a análise de $O$ som ao redor, Aquarius e Bacurau; e por fim, propondo uma interpretação de possíveis encontros e desencontros dessa tríade com os três principais capítulos sociopolíticos que marcaram a história brasileira na última década: os protestos de 2013, o golpe jurídico-parlamentar de 2016 e a eleição de Jair Bolsonaro em 2018.

Assim, a despeito de inúmeras apreciações críticas já feitas sobre os três longas-metragens do cineasta (Rabello 2015; Milão 2019; Araujo 2019; Azerêdo 2020; Xavier 2021, entre outros) e dos estudos que abordam ou enfatizam os arranjos objetivos e históricos da sua produção e da cena de cinema contemporânea de Pernambuco (Paiva 2008; Nogueira 2009; Nogueira 2014; Prysthon 2017; Teixeira Neto 2018; Santos 2019, entre outros), este ensaio busca conjugar 
organicamente essas duas vertentes. Ou seja, ao mesmo tempo que os filmes são considerados frutos das escolhas feitas por um sujeito historicamente situado, o que geralmente escapa ou é secundarizado em uma abordagem formalista, também se atentará para as suas especificidades formais e para fatores que muitas vezes não são focados pela lente "sociológica". Acredita-se que esse ângulo analítico lança nova luz no caráter paradoxal das práticas de Kleber Mendonça Filho especialmente prolíficas para se pensar o Brasil e o capitalismo contemporâneo -, e pode vir a contribuir não só para o campo de estudos do cinema brasileiro, mas também para uma reflexão sobre os desafios políticos prementes do país.

\section{Formas de ler a relação entre cinema e política}

Ainda que não faltem esteticistas que busquem salvar a fruição estética negando qualquer relação cinema-política, pode-se dizer que todos os filmes são políticos, uma vez que se tratam de transfigurações do real portadoras de conceções de mundo e imaginações coletivas. Nesse sentido, comédias românticas pasteurizadas são tão políticas quanto os filmes que habitam o circuito de festivais, a se somar os sentidos atribuídos a partir das suas respetivas receções. Aqui, portanto, assumese a posição que parece ter marcado o que se entende por cinema político no Brasil: a interconexão entre linguagem estética e disposição específica relacionada a um engajamento crítico e social dos realizadores. Dito isso, é ainda necessário esclarecer que, nesse campo voltado aos dissonantes, há diferentes posturas e tradições analíticas em torno da relação entre cinema e política.

Entre os que pensam o cinema brasileiro contemporâneo, duas correntes são centrais. A primeira, essencialmente vinculada à tradição ensaística brasileira, é uma prolífica e consolidada vertente que considera o social como um fator de arte (Cândido 2006), ou seja, parte da análise imanente para estabelecer a correlação entre forma e conjuntura (Saraiva 2013; Xavier 2006; Nagib 2006; Ramos 2002; Pellegrini 2008; Oricchio 2003, entre outros). A segunda, que vem demonstrando um expressivo crescimento, parte das condições sociais de realização, ora detendo-se nos seus aspetos materiais, relacionados à cadeia produtiva, mercado cinematográfico, rotinas de produção, processos de institucionalização, políticas públicas e trajetórias sociais dos produtores, ora estabelecendo intercâmbios com os aspetos 
formais das obras (Oliveira 2014; Ikeda 2011; Marson 2009; Costa 2017; Ridenti 2014, entre outros). Os primeiros, ao buscar nos filmes as categorias estéticas que conferem expressão à forte relação entre o interno e o externo, estabelecem os vínculos de alcance mais amplo no debate cultural a partir da singularidade das obras. Já esses últimos se debruçam predominantemente sobre a dinâmica de funcionamento do campo cinematográfico, demarcando e apontando as suas contradições, pressões e, em alguns casos, a maneira como se encontram transfiguradas na forma estética. ${ }^{5}$

O trajeto sugerido por Raymond Williams (2007) desde o cultural materialism, ${ }^{6}$ ao deslocar o foco do impasse entre a abordagem que parte da imanência e a que principia na conjuntura em direção às práticas, talvez nos indique "a terceira margem do rio". Em uma metáfora inspirada nesse famoso conto do escritor João Guimarães Rosa (2001), pode-se dizer que a aceção williamsiana em muito se assemelha ao conjunto da imagem rio-remador. $\mathrm{O}$ rio (essencialmente mutante) - que torna possível o ato de remar, confere-lhe sentido e, por vezes, dita o seu ritmo - é o mesmo que testemunha a beleza do gesto único e singular do remador a interferir na sua rotina natural. Este último, simultaneamente, além do esforço que requer a ação engajada junto ao remo, também experimenta vivamente o balanço das águas por fora e por dentro, com todos os seus sentidos. Nessa analogia, o rio é a conjuntura e o gesto de remar a forma estética irredutível, sendo a ação, ou seja, a prática, a tessitura comum que as articula. Mas no caso da criação cinematográfica, o remador não está só (mesmo nos chamados filmes de autor) nem no sentido específico, porque necessita de uma equipe geralmente numerosa, nem no sentido amplo, porque nenhum artista está desvinculado das relações sociais que atravessam, formam e informam a sua experiência de vida.

\footnotetext{
${ }^{5}$ Há ainda uma vertente pós-moderna, que mesmo quando se coloca como refratária, permanece vinculada (em maior ou menor grau) a categorias tradicionais da primeira corrente citada. Nela, percebe-se um deslocamento da perspetiva política. Os filmes passam a ser vistos menos como representação e mais (ou exclusivamente) como acontecimentos produtores de discursos de visibilidades e sensibilidades que se contrapõem ao atual estado de exploração e sujeição, numa visão mais fragmentada dos protagonistas sociais (França 2003; Rossini 2007; Bentes 2019, por exemplo).

${ }^{6}$ Williams fez parte de uma ampla corrente interdisciplinar conhecida como Nova Esquerda Britânica da qual também participaram nomes como E.P. Thompson, Eric Hobsbawm e Stuart Hall, cujos escritos propuseram uma renovação do pensamento marxista (cf. Rivetti 2020).
} 
Assim, para Williams, os estudos da relação arte-sociedade devem partir das práticas a fim de detetar a agência social envolvida, acessível nas suas especificidades internas, sociais e históricas em simultâneo. Isso implica escavar a consciência prática e as filiações reais estabelecidas, em um complexo variável, com o objetivo de definir, da forma mais precisa possível, as intenções sociais e políticas portadas por dada produção cultural, pois,

à medida que descobrimos a natureza de uma prática determinada, e a natureza da relação entre um projeto individual e uma modalidade coletiva, vemos que estamos analisando, como duas formas do mesmo processo, tanto sua composição ativa quanto as condições dessa composição, e em ambas as direções trata-se de um complexo de relações extensivas e ativas. (Williams 2005)

Esse percurso, além de aclarar os problemas decorrentes do perigo iminente de que fala Jameson, também capta o que busca escapar e desafina, ou seja, as práticas de produção e formas de práticas emergentes. Afinal, por maior que seja o poder de incorporação da cultura dominante (ela mesma em processo contínuo de reelaboração), essa hegemonia não consegue abocanhar e controlar tudo no movimento incessante de luta pelos sentidos sociais e políticos na cultura. O cinema político está sujeito, portanto, a essa grande variação histórica que configura o seu grau de oposição ou anuência, no seu processo também contínuo de reelaboração. Daí a importância de rastrear as condições das suas práticas, de maneira a reconhecer a correlação existente entre o filme como criação autoral e um sistema coletivo. Por isso, antes de adentrar no gesto singular de Kleber Mendonça Filho, é necessário primeiro enunciar a remação da qual ele faz parte. A "canoa" do cineasta está inserida na cena contemporânea de cinema de Pernambuco, ainda mais próxima das práticas da segunda geração de realizadores que despontou, a partir do início do século XXI, em Recife. Dessa cena brotaram, dentre outros, títulos marcantes como Amarelo Manga (2003), Cinema, Aspirinas e Urubus (2005), Tatuagem (2013), Um Lugar Ao Sol (2009), Pacific (2009), Eles Voltam (2012) e A História da Eternidade (2014). 


\section{A remação do cinema Pernambucano}

O início dessa prestigiada cena foi resultado da disposição e reunião de um grupo de amigos que se conheceu nos tempos da universidade, entre os quais estavam os cineastas Paulo Caldas, Lírio Ferreira, Marcelo Gomes, Hilton Lacerda, Adelina Pontual e Cláudio Assis. Muito próximos do pessoal da música envolvido com o nascente Manguebeat, também decidiram "injetar ânimo" no cinema local, recarregando as suas baterias após a lacuna deixada com o fim do movimento Super 8 de Recife (Figueirôa 2000) e no contexto de desânimo generalizado que marcou a quase extinção do cinema nacional durante a presidência de Fernando Collor (1990-1992). ${ }^{7}$ O longa de ficção Baile Perfumado (1996) foi a festa que objetivou essa vontade e, ao mesmo tempo, principiou o processo de fundação das bases da atual produção profissional de cinema em Recife (Nogueira e Cunha Filho 2016).

Essa primeira geração compartilhou ativamente experiências comuns vivendo numa capital que se superurbanizava rapidamente. Sintonizada na frequência da globalização e do processo neoliberalizante recémdesembarcado no país, Recife, no entanto, continuava fortemente afundada na lama da pobreza e das desigualdades sociais. A partir dessas vivências, o grupo estabeleceu um intenso diálogo com seu próprio tempo, portando todo um "sistema de possibilidades herdadas" (Bourdieu 1996, 235): das dinâmicas históricas do riquíssimo campo intelectual e artístico de Pernambuco até a configuração do cinema local e suas múltiplas relações com o eixo Rio-São Paulo (que concentra historicamente o maior volume de produção dos filmes brasileiros) desde os anos 1920 (Bernardet 1970; Araújo 1997; Cunha Filho 2010). Assim, nutrida por uma herança, essa geração empreendeu uma verdadeira investigação da convivência dos elementos modernos e arcaicos na chave da contraposição (sertão/capital, velho/novo), conjugando a ela a defesa da inovação da linguagem que, por sua vez, expressou simultaneamente recusa e adesão aos signos da indústria

\footnotetext{
${ }^{7}$ Fernando Collor de Melo, primeiro presidente eleito democraticamente após a ditadura militar brasileira, foi deposto em 1992 por meio do impeachment. Nos dois anos que esteve na presidência, ele rebaixou o Ministério da Cultura a Secretaria e extinguiu vários órgãos culturais, a exemplo da Embrafilme (Empresa Brasileira de Filmes S.A.), sem qualquer política substitutiva, o que gerou um vazio produtivo na cinematografia brasileira. Tanto que, em 1992, apenas dois filmes de longa-metragem foram lançados no país (Nagib 2002).
} 
cultural então consolidada no país. De forma homóloga, também assumiram essa postura no campo da produção cinematográfica, buscando preservar a liberdade estética conjugada ao compromisso de estabelecer o estofo profissional da cena atrelado à preocupação em comunicar e em exibir os filmes nas salas de cinema.

Esse horizonte está presente no notável esforço de organização política de que participou essa geração em torno da luta pela viabilização de meios e recursos, tanto na esfera local, da qual resultaram, por exemplo, importantes conquistas no Funcultura, ${ }^{8}$ quanto no âmbito nacional, junto a outros cineastas "independentes", no contexto dos recém-criados mecanismos de regulação e fomento estatais instituídos a partir dos anos 2000, como a Ancine. Sem dúvida, as águas em que o cinema político contemporâneo passou a navegar já não eram as mesmas das vanguardas dos anos 1960. Portanto, não é exclusividade de Pernambuco o evidente deslocamento do sentido militante daquele momento para uma atuação mais pragmática (em menor ou maior grau) a partir dos anos 1990, aí incluídos, além dos cineastas, os críticos e intelectuais do meio. No entanto, sublinhe-se a configuração específica das práticas dos diretores da Retomada ${ }^{9}$ em Pernambuco, os quais, mesmo vindos de estratos medianos/inferiores da classe média recifense, sem serem herdeiros de capital social e cultural facilitadores de entrada no setor, conseguiram "fundar" as condições necessárias para fazer filmes na periferia do campo cinematográfico da periferia do capitalismo.

Driblar a falta e a distância dos recursos económicos, técnicos e de formação só foi possível por conta de uma lógica de associação assentada na amizade, nas afinidades, valores e sentimentos compartilhados, que em muito se diferencia da rotina estritamente profissional do modo do cinema industrial, pautado na hierarquia e superespecialização. A chamada por eles "brodagem" (Nogueira 2014) é um tipo de trabalho colaborativo através do qual um ajuda no filme do outro, preservando a assinatura autoral. Apesar da diversidade palavra, aliás, que também designou uma característica elementar da

\footnotetext{
${ }^{8}$ Principal mecanismo de fomento cultural de Pernambuco instituído em 2002.

${ }^{9}$ A chamada Retomada do Cinema Brasileiro, ainda que não seja um termo consensual, foi a nomenclatura utilizada para caracterizar a recuperação da atividade cinematográfica em meados dos anos 1990 no país, referindo-se, sobretudo, ao aumento quantitativo do número de filmes produzidos.
} 
Retomada -, os filmes dessa geração revelam, em diferentes estilos, as condições dos marginalizados e subalternizados, atentando para as contradições que os tocam e para as que os fraturam entre si. Essa representação, marcada pela cautela em narrar o "outro", manifesta-se em uma versão de denúncia e atualiza a continuação do compromisso político a partir da lógica do encontro e de destinos interligados.

Esse chão já fertilizado viu brotar, a partir do começo do século XXI, uma nova geração de cineastas agrupados em torno de produtoras, as quais passaram a funcionar mais ou menos próximas da dinâmica de coletivos. Esses realizadores mantiveram e, de muitas maneiras, reforçaram a lógica de associação colaborativa já citada. Não à toa, o título do primeiro longa de ficção dessa geração, Amigos de Risco (2007), foi rodado efetivamente na lógica da "brodagem" durante a madrugada, com uma pequena equipe, sob risco real de assalto e com um orçamento de curta-metragem. Nomes como Marcelo Pedroso, Gabriel Mascaro, Daniel Bandeira, Juliano Dornelles, Leonardo Lacca, Tião e Marcelo Lordello já incursionaram na linguagem cinematográfica auxiliados pela internet e pela tecnologia digital, as quais democratizaram e facilitaram a produção fílmica. Esses sujeitos adentraram o campo em um contexto de maior disponibilidade de recursos e editais públicos, mas também de maior concorrência, dado o crescimento do número de realizadores e mão de obra especializada. Além do mais, se, por um lado, o mercado cinematográfico brasileiro vê a ampliação e diversificação da produção, por outro, é cada vez mais pressionado pelo crescimento do sistema multiplex, pelo fechamento dos cinemas de rua, pelo encarecimento dos ingressos e pela restrição crescente de acesso às salas dominadas pelos blockbusters internacionais e nacionais (pertencentes, na sua maioria, ao catálogo da Globo Filmes) devido à atuação das majors. ${ }^{10}$ Nesse cenário, a proliferação dos festivais e da cadeia alternativa de legitimação acabou por atrair a nova geração, adquirindo centralidade para o grupo, por estarem muito mais compromissados com a experimentação da linguagem estética e com a autoralidade.

\footnotetext{
${ }^{10}$ A exemplo da Association of America (MPAA), composta por membros como Walt Disney Studios Motion Pictures, Paramount Pictures Corporation, Sony Pictures Entertainment Inc., Twentieth Century Fox Film Corporation, Universal City Studios LLC e Warner Bros. Entertainment Inc., que controlam grande parte do setor de exibição e distribuição, e também participam da produção do mercado nacional brasileiro (Melo e Galiza 2014).
} 
Além disso, os mais jovens, que se aliaram aos pioneiros na atuação política de classe em Pernambuco, começaram suas carreiras quase no mesmo momento em que se iniciou o ciclo petista (2002-2016), ou seja, de governação do Partido dos Trabalhadores (PT). Esse foi um período de contradição imanente no plano económico-político: a melhoria das condições de vida dos mais pobres esteve atrelada à garantia dos preceitos e dos modos operanti neoliberais, em uma espécie de terceira via à brasileira, ou ainda, em uma nova versão da problemática explosiva de "modernização e democratização" de que falou Roberto Schwarz $(1978,65)$.

Essa dinâmica afetou significativamente a similaridade de situação vivida por esse grupo geracional, que cresceu imerso em uma Recife de arranha-céus já superurbanizada, na qual os fossos sociais passaram a ser demarcados cada vez mais por muros, paredes de concreto e vigilância condominial. É esse urbano que habita fortemente as suas imagens, funcionando como um tecido interno gerador de significados das obras. Também parece ser essa a matéria da interconexão estabelecida por eles entre o local-nacional-transnacional; afinal, a mundialização da cultura na atualidade, em grande medida, é formada pela metropolização dos signos e modos de vida.

Dessa maneira, em uma grande variedade de estilos, os mais jovens vindos de frações medianas/altas da classe média recifense - se afastam da lógica do encontro da primeira geração a fim de se "representarem a si mesmos" e, a partir dessa perspetiva, apontarem para as dissonâncias e os tensionamentos existentes nos seus próprios espaços sociais e para além deles. Parecem enfatizar mais o caráter simbiótico do que contrastante entre os pares velho/novo ou moderno/atrasado, por meio da chave da negação e de um sentimento compartilhado de alerta.

Kleber Mendonça Filho está situado centralmente e compartilha dos valores, modo de produção e formas de prática da segunda geração desde os seus primeiros curtas-metragens, a exemplo de Eletrodoméstica (2005) e Recife Frio (2009), podendo mesmo ser considerado um mentor dos mais jovens, dada a influência que exerceu na formação de muitos deles. No entanto, além da importância que confere ao circuito dos festivais, também demonstra uma forte afinidade com a primeira geração ao compartilhar de sua preocupação com a ocupação das salas de cinema e com o alcance de público. Talvez isso se deva à especificidade da sua atuação profissional, pois, antes de 
se tornar diretor, foi crítico de cinema por 12 anos e trabalhou na coordenadoria do Cinema da Fundação Joaquim Nabuco por 18 anos, período em que manteve o objetivo de estabelecer uma política de formação de público (Barros 2017). Essa trajetória lhe possibilitou formar um rico acervo de conhecimentos e capital social em torno das dinâmicas presentes em diferentes esferas: no campo cinematográfico durante a Retomada, o que de certo lhe forneceu um mapa das obras e dos seus diálogos (ou não) com a história do cinema brasileiro; no circuito de festivais, que também lhe propiciou um mapa do cinema mundial, bem como dos seus estatutos e normas implícitas, como explicita seu longa documentário Crítico (2008); e na cena de Recife (passado e presente), já que esteve envolvido diretamente no seu fomento e divulgação.

Especificado o sistema coletivo, passemos ao objetivo de definir melhor o gesto singular das práticas de Kleber Mendonça Filho na trilha dos seus três longas-metragens, mesmo que a partir de descrições e análises sumárias. Isso porque apenas essa visão de conjunto é capaz de revelar a profícua relação que a sua filmografia estabeleceu não só, mas especialmente, com a sociedade e a realidade política brasileira na última década.

\section{A remação de Kleber Mendonça Filho}

Kleber Mendonça Filho não apenas filmou a própria rua no bairro do Setúbal, mas também transformou o apartamento em que morava há 25 anos em uma das locações de $O$ som ao redor (2012). No filme, a narrativa identifica e constrói uma complexa rede de pertencimento social a partir de uma investigação dos espaços privados de habitação em contato ou atrito com a rua, ou seja, com o espaço público. Isso é feito desde núcleos centrais. Em torno do primeiro deles, Francisco (Waldemar José Solha) - antigo dono de engenho, representante da elite proprietária rural que agora mora em um apartamento duplex e é dono de mais da metade dos imóveis da área -, orbitam outros membros da família, tais como o neto, João (Gustavo Jahn), que gerencia o negócio imobiliário do avô; o filho, Anco (Lula Terra), cuja nostalgia do passado o faz preservar a casa de muro baixo e construção antiga da paisagem reinante de prédios, mas não o impede de instalar um moderno sistema de vigilância; e o neto, Dinho (Yuri Holanda), que se afasta da responsabilidade de gerir os negócios familiares, assumindo 
apenas a blindagem advinda da herança para cometer, sem riscos de punição, desvios ilícitos. Mais abaixo na escala social, encontra-se uma típica família de classe média composta pelo marido, pelos filhos, Fernanda (Clara Pinheiro de Oliveira) e Nelson (Felipe Almeida), moradores de um apartamento de estilo residencial, que giram em torno da mãe, Beatriz (Maeve Jinkings). É ela que tem a rotina de limpar a casa, administrar a diarista e os horários das atividades dos filhos, atormentada pelos latidos do cachorro do vizinho. Quase ocultado, também se nota um estrato social inferior ao da família de Beatriz na personagem do garoto que joga bola com Nelson e mora em um conjunto habitacional. Por fim, o núcleo que habita a rua na qual chega Clodoaldo (Irandhir Santos) e sua equipe, oferecendo o serviço de segurança privada para os moradores, o qual é composto por trabalhadores formais, geralmente as empregadas domésticas dos apartamentos, e outros tantos informais, como vendedores ambulantes e guardadores de carros vindos de bairros populares.

O som ao redor, em um jogo de ruídos e silêncios, ou melhor, buscando absorver o que ambos ocultam, enfatiza as tensões desse universo. Tensões estas que não se referem apenas ao presente, mas ecoam o passado histórico brasileiro de espoliação. A intersecção entre o visível e o invisível, entre o presente e o passado, é alcançada formalmente, em grande medida, pelo diálogo estilístico que Kleber Mendonça Filho estabelece com o cinema de género. Ele se vale do suspense e do horror como suportes de tradução da semântica social presente na narrativa, desde o fantasma da escravidão, que continua a assombrar o presente no forte marcador racial das desigualdades e violência atuais, passando pelos desejos reprimidos de ascensão, conjugados ao medo de declínio social que intranquilizam a classe média, até os receios prementes das classes altas diante das ameaças ao seu domínio e proteção do legado assentado nas cercas, nos muros e nas divisões hierárquicas de poder. Clodoaldo e o irmão, na verdade, foram vítimas desse legado e voltam disfarçados em busca de vingança. O barulho das bombas acesas pela família de Beatriz para assustar o cachorro do vizinho, na cena final, oculta o som do tiro que consuma o acerto de contas entre Clodoaldo, seu irmão e Francisco, encerrando o filme em um tom agudo.

Dessa maneira, $O$ som ao redor parece sugerir uma relação ou interferência de determinados estratos da classe média no acerto de contas entre os subalternos e a elite. Representados centralmente pela figura de Beatriz, seus valores e modo de vida são nitidamente 
criticados. Stressada e infeliz com a própria rotina que poderia ser outra, a personagem busca, desesperadamente, os prazeres castrados presentes na defesa do próprio status, assentado nos princípios do consumo como distinção (i.e., na cena em que se masturba utilizando o modo centrifugar da máquina de lavar), na performance hipócrita de um papel social (como demonstram os artifícios empregados para a compra e uso não admitidos da maconha) e no plano de conversão de capital cultural em ganho económico futuro por meio dos herdeiros (a exemplo do cálculo das vantagens do acréscimo de mais um idioma na lista de cursos dos filhos). O filho Nelson é o único que demonstra desconforto e discordância em relação ao habitus familiar, o que também é expresso no plano americano da cena final, em que pai, mãe e filha se abraçam, ao passo que ele, no canto esquerdo do quadro, mais à frente, tapa os ouvidos e abaixa a cabeça, protegendo-se do barulho e da luz.

A grua do olhar de $O$ som ao redor desce e assume uma perspetiva mais rasteira, propriamente "de dentro", em Aquarius (2016). Agora participamos intimamente da vida de Clara (Sônia Braga), última moradora de um prédio multifamiliar da orla do Pina. Ela se recusa a vender seu apartamento à construtora Bonfim, que planejou demoli-lo para construir em seu lugar um edifício supermoderno. Recursos formais anti-ilusionistas, como o uso de letreiros para demarcar os capítulos do enredo e o zoom, estão também presentes no longa, que se vale da apropriação estilística do género suspense/horror tanto para reforçar a perseguição a Clara quanto para explicitar as rachaduras internas do universo social da personagem. Isso porque ela é apresentada como parte das contradições da sociedade brasileira, das quais - apesar da lucidez diante de seus aspetos regressivos - participa estruturalmente, a exemplo da relação estabelecida com as empregadas domésticas. Ainda assim, a postura e os valores da jornalista aposentada, especialista em música brasileira, se opõem largamente às atitudes da personagem Beatriz de $O$ som ao redor. $\mathrm{O}$ apartamento arejado, iluminado, repleto de móveis, livros, vinis e objetos de valor afetivo traduzem os princípios de Clara, afinados ao prazer genuíno da troca humana, experiência compartilhada com forte participação da memória, valorização da arte e da cultura adquirida, bem como dos afetos e, portanto, contrapostos ao novo ethos destituído de sentido humano e ao dinheiro como valor universal de exercício do poder. 
Em Aquarius, Kleber Mendonça Filho narra, sobretudo, seu próprio círculo social por meio da protagonista e de sua família. Trata-se de uma fração da classe média intelectualizada e esclarecida, em parte proprietária, que assume explicitamente uma postura política progressista e compartilha, em menor ou maior grau, dos valores defendidos pela personagem interpretada por Sônia Braga. Também é inegável que Clara, em muito, ecoa a mãe do cineasta, Joselice Jucá, falecida em 1995, que, assim como a personagem, também teve câncer. Historiadora e especialista na temática "movimento abolicionista”, ela foi a responsável por familiarizar o filho nos temas da formação social brasileira e é sempre citada por ele como sua principal inspiração de vida (Nascimento e Veras 2019).

Na luta contra as investidas do dono da construtora, de Geraldo (Fernando Teixeira), e de seu neto, Diego (Humberto Carrão), Clara tem ajuda de uma rede de amigos e trabalhadores que a apoiam, entre eles o bombeiro Roberval (Irandhir Santos), que descobre uma colónia de cupins implantada propositadamente no prédio para forçar a sua retirada. Mas apesar dessa ofensiva para expulsá-la do local, na cena final, ao lado do sobrinho, do irmão e da advogada, a personagem reafirma a sua posição de permanecer no apartamento, mostra as provas que colheu contra a construtora e joga sobre a mesa uma amostra do cupim de demolição, suscitando o apoio e a vibração do espectador.

Bacurau (2019), codirigido com Juliano Dornelles, parceiro e amigo que já havia feito a direção de arte de $O$ som ao redor e Aquarius, reaviva uma importante imagem-síntese presente na ficção nacional, a qual funcionou como um elo especial entre estética e política no cinema moderno brasileiro: o sertão. O povoado de Barras, no Rio Grande do Norte, se tornou Bacurau, a cidade que, em uma distopia futurista brasileira, desaparece do mapa, ou melhor, das imagens de satélite, para se tornar palco de uma chacina, de um safari que caça os seus moradores, cujas vidas são contabilizadas em pontos pelo grupo de estrangeiros liderado por Michael (Udo Kier), um estereotípico sniper americano. O grupo que agora exercita o assassinato como esporte no sertão brasileiro é uma versão atualizada, particularmente cruel, conservadora e bem equipada, dos antigos pistoleiros americanos que mataram milhares de indígenas no avanço para o oeste. Na diegese, a caça em Bacurau tem o apoio do prefeito local, Tony Júnior (Thardelly Lima), que, apesar de manter a fachada populista, consente o 
extermínio, e de um casal de sulistas (Antonio Saboia e Karine Teles), logo eliminados por se considerarem "iguais" aos demais membros do grupo "gringo". Mas Bacurau aciona os seus ícones coletivos de resistência, nutrindo-se da força da tradição (na figura da matriarca Carmelita, interpretada por Lia de Itamaracá), da memória histórica e da estratégia conjunta para proteger a vida dos seus moradores: Pacote (Thomas Aquino) e o bando de Lunga (Silvero Pereira), em versões atualizadas dos antigos cangaceiros, tomam a frente da reação tática e da legítima violência dos oprimidos face ao gozo sádico dos seus inimigos.

De forma semelhante, também Kleber Mendonça Filho e Juliano Dornelles se valem de um variado acervo formal/estético/ideológico do cinema nacional e do cinema mundial, conferindo-lhe interpretação própria. Isso por meio da escolha central da alegoria, pois Bacurau, apesar de se passar em um tempo futurístico, condensa uma verdadeira sociogénese da nação brasileira, das suas raízes coloniais, desigualdades e violências históricas, ao mesmo tempo em que situa as suas formas reincidentes no presente, tanto das fronteiras das grandes metrópoles, quanto nas dos “sertões” do país. Essa representação é alcançada por meio do uso específico que se faz do género western, além de citações dos spaghetti, filmes de máfia, de guerra e de signos largamente reconhecidos do cinema comercial. Há em Bacurau uma deglutição desses signos, de referência tropicalista, ao mesmo tempo em que se preserva a dualidade para demarcar a diferença entre dominantes e dominados, opressores e oprimidos, numa aproximação clara com a tradição da arte engajada dos anos 1960. Esse antagonismo que adere ao tom irónico em relação ao grupo liderado por Michael, a quem vários clichês do cinema americano são atribuídos, em muito difere da complexidade da comunidade de Bacurau, que é aberta às diferenças e contradições. Esse mecanismo formal funciona, assim, como um artifício consciente (e didático) de elucidação do antagonismo, conflito e, como bem disse Jean-Claude Bernardet, como anteriormente citado, da luta de classes.

A conjugação entre liberdade e comunicação também parece ter sido a estratégia assumida por Kleber Mendonça Filho no que concerne às suas práticas de produção ao longo da última década. Na tentativa de transpor os limites que se ergueram entre o "filme de festival" e as salas comerciais de cinema, o prestígio advindo dos festivais e da crítica especializada, de certo, foi a medida da parceria firmada com a Globo 
Filmes a partir de Aquarius. ${ }^{11}$ Dessa maneira, Kleber manteve a liberdade autoral ao mesmo tempo que conseguiu impulsionar a exibição dos seus dois últimos longas nas salas brasileiras, além de exibi-los na televisão em cadeia nacional.

Acompanhado disso, em Aquarius nota-se um crescimento dos orçamentos que se distanciou da média praticada pela segunda geração de Pernambuco e se aproximou da de alguns títulos do grupo da Retomada, equiparando-se à média do circuito comercial do eixo Rio/São Paulo em Bacurau. ${ }^{12}$ Nesses dois filmes, nos quais participaram atores e atrizes reconhecidos nacionalmente, também se percebe que as equipes se complexificaram e se tornaram mais numerosas pela ficha técnica. Esses, sem dúvida, são um indício de uma maior distância da lógica de associação mais integrada e próxima da "brodagem" da segunda geração.

Além do mais, o facto de Kleber Mendonça Filho ter aceitado o convite em 2016 para assumir a coordenação de cinema e programação das salas do Instituto Moreira Salles no Rio de Janeiro e em São Paulo, ainda que tenha permanecido em Recife, ${ }^{13}$ expressa a estratégia de ampliação de influência também no âmbito da curadoria e formação de público. ${ }^{14}$ Porém, não se pode esquecer que a arte política é um processo repleto de "tensões e acomodações" (Cândido 1984, 35) e, como nos desafia a proposta analítica de Raymond Williams e afirma Antônio Cândido, uma "análise mais completa mostra como o artista e o escritor aparentemente cooptados são capazes, pela própria natureza

\footnotetext{
${ }^{11}$ Ressalte-se que, em 2013, o diretor executivo Carlos Eduardo Rodrigues, protagonista da polêmica com Kleber Mendonça Filho veiculada pela imprensa, foi substituído por Edson Pimentel.

${ }^{12} \mathrm{O}$ som ao redor custou R \$ 1,7 milhões (Mendonça Filho 2018); Aquarius R\$ 3,4 milhões (Hermsdorff 2016); e Bacurau R\$ 8 milhões (Mendonça Filho 2020).

${ }^{13}$ IMS. 2016. "Kleber Mendonça Filho no IMS". Blog do IMS. Última modificação em 5 dezembro de 2016. https://blogdoims.com.br/kleber-mendonca-filho-no-ims/

${ }^{14}$ A ida para o IMS, instituto gerido pela família Moreira Salles - de que fazem parte os também cineastas Walter Salles e João Moreira Salles - e, portanto, vinculado ao Itaú Unibanco, não deixa de expressar uma tendência mais geral da dinâmica do campo cultural brasileiro. A influência e atuação do mercado financeiro em diferentes áreas culturais e educacionais, mediadas por políticas públicas via leis de incentivo, tende a se aprofundar em um cenário de crise político-econômica, esvaziamento institucional, escassez de editais públicos e fontes de financiamento. Cf. Itaú Cultural, Dez anos de Economia da Cultura no Brasil e os Impactos da Covid-19: um relatório a partir do painel de dados do observatório Itaú Cultural. (São Paulo, Itaú Cultural, 2020). É provável que esses fatores, somados à concentração no aporte de recursos e à ampliação do controle dos agentes financeiros no setor - cujo papel de principal polo de atração dos artistas e produtores estabelecidos será muito provavelmente reforçado -, afetarão de forma objetivamente mais intensa as cadeias mais vulneráveis da cultura, o que incidirá em uma consequente retração da diversificação de obras, permanência dos trabalhadores na área e entrada de novos autores no campo intelectual.
}

aniki Ensaios | Essays 
da sua atividade, de desenvolver antagonismos objetivos, não meramente subjetivos, com relação à ordem estabelecida" (2009, 36). Ao propor um necessário acerto de contas com o passado brasileiro e dessincronias sociais, das quais não escapa a sua própria classe, Kleber Mendonça Filho se movimenta justamente nesse complexo terreno.

\section{A política brasileira da última década em três atos}

A preservação do ímpeto de insubordinação faz com que a obra de Kleber Mendonça Filho compartilhe do traço comum a todo o cinema de Pernambuco: é uma criação contemporânea, no sentido apregoado por Giorgio Agamben (2009), porque busca se afastar das luzes que emanam de seu próprio tempo para lhes capturar as sombras. No entanto, a singularidade de Mendonça Filho demonstra um grau talvez mais elevado desse aspeto, ao tornar a história motor interno das narrativas e ao reavivar as memórias insurretas da modernidade. Ademais, como se pode perceber nas sintéticas descrições realizadas dos filmes, ressoam neles ecos de clássicos do pensamento social brasileiro, a exemplo da tese da prevalência dos afetos e da esfera doméstica na vida política nacional, de Sérgio Buarque de Holanda; da ênfase analítica espacial de Gilberto Freyre para pensar o país; e do realce da leitura objetiva da vida económica nacional de Caio Prado Junior.

A relação entre filme e sociedade não é de espelhamento, mas pode ser mais ou menos intensa, a depender das suas formas práticas (estéticas e de produção) através e nas quais figuram, representam, catalisam e respondem à realidade social. De forma semelhante aos letreiros utilizados para separar os capítulos de $O$ som ao redor e Aquarius, a tríade que inclui Bacurau parece cumprir a mesma função em relação aos três principais capítulos sociais e políticos da última década no país: os protestos massivos de 2013 (as chamadas jornadas de junho); o golpe jurídico-parlamentar que destituiu a presidenta Dilma Rousseff; e a conquista do poder pela extrema direita na figura de Jair Bolsonaro. A própria receção dessa filmografia, marcada pela vinculação das obras ao cenário político em termos de apreciação estética e implicações extraestéticas, como demonstram alguns fatos citados na abertura desse artigo, também é um indício contextual do grau de intensidade da relação desses filmes com a realidade sociopolítica brasileira. 
Os três longas são exemplares da capacidade da arte de detetar e traduzir movimentos sociais, subjetivos e políticos ainda subterrâneos. Talvez pela forte relação estabelecida com o suspense - cujo efeito de tensão e medo advém da administração da expectativa, em um jogo com o oculto acionado por um conjunto de artifícios de composição da cena, a exemplo da música, da fotografia e do cenário -, os filmes funcionaram como verdadeiros radares da sociedade e política brasileiras nesse último período. O tensionamento acumulado e até então não explicitado, após mais de uma década de governos petistas, explodiu em manifestações massivas Brasil afora em 2013, deflagradas por atos contra o aumento da tarifa do transporte público em algumas capitais. Os protestos, provenientes de legítimos anseios sociais diante da perda de direitos, frustração das expectativas de melhoria de vida e esgarçamento do tecido social, tiveram, no entanto, suas demandas populares capturadas por velhas forças conservadoras que convocaram, em especial, as frações ressentidas da classe média a também ocuparem as ruas, como apontam Sávio Cavalcante (2020) e Marcelo Ridenti (2018).

Se na cena final de $O$ som ao redor não ouvimos efetivamente o som do tiro e sim o das bombas, de forma semelhante, o anunciado acerto de contas entre as classes populares e a burguesia, que aprofundava o projeto de absorção dos aparelhos de Estado, foi interrompido com forte interferência dos estratos médios correspondentes àquele da personagem de Beatriz. É como se o suspense, ou melhor, as tensões crescentes entre classes, os desejos reprimidos e as desilusões inadiáveis dos anos anteriores tivessem vindo à tona. Contudo, a ofensiva do capital financeiro internacional e burguesia a ele associada, principal força política dirigente do golpe, foi maior (cf. Martuscelli 2020). Não sem contradições, as frações burguesas, com o aporte do Congresso Nacional e do aparato judicial, mobilizaram os seus instrumentos de poder, em especial o Congresso Nacional e o sistema judiciário, rompendo o pacto com o governo historicamente ligado à classe trabalhadora.

Assim, ao golpe, conduzido como um processo de impeachment, que afastou Dilma Rousseff da presidência da República, foi acoplada a prisão do ex-presidente Luiz Inácio Lula da Silva, em 2018, tornando-o inelegível para concorrer às eleições desse mesmo ano. Em muito, tanto as contradições da personagem Clara, quanto a sua luta contra a construtora Bonfim podem ser comparadas ao processo que culminou 
no golpe de 2016. A tentativa de expulsão da construtora, valendo-se das artimanhas mais vis, inclusive "plantando" cupins propositadamente no prédio a fim de desmoroná-lo por dentro, pode ser considerada equivalente a toda sorte de confabulações parlamentares utilizadas para descredibilizar e incriminar a então presidenta. A diferença é que Dilma Rousseff, diferente da personagem Clara, não teve apoio popular e nem conseguiu mover o campo político a seu favor, o que evidenciou a insustentabilidade e os limites da política pactualista levada a cabo pelo PT até aquele momento.

O resultado dessa derrota se completa com a eleição de Jair Bolsonaro, em 2018, quando as mesmas forças responsáveis pelo golpe admitem o representante-ícone da vertente mais regressiva da extrema direita no poder, em troca da garantia de radicalização neoliberal, a exemplo da reforma trabalhista, aprovada durante o governo interino de Michel Temer, e da Reforma da Previdência, já sancionada na era Bolsonaro. Assim, testemunhamos mais uma vez na história brasileira a "revolta da província" (Schwarz 1978) e o desfile de suas figuras ressentidas, interesseiras e fardadas a avançar contra toda sorte de conquistas sociais. Porém, agora os seus discursos moralistas de Deus, pátria e família acompanham uma singular política de destruição antimodernizadora, sendo plenamente conciliáveis com a submissão ao imperialismo neoliberalizante do capital internacional. A esse desenredo político somou-se, em 2020, a substancial piora das condições socioeconómicas e de saúde, brutalmente agravadas pela pandemia do vírus SARS-COV-2 (Kliass 2021).

A lógica dominante do capitalismo - que já cumpria a ordem de marginalizar, espoliar, explorar, financeirizar a vida, estimular a competição e individuação, como já apontaram diversos autores, a exemplo de David Harvey (2020) e Fredric Jameson (1997), ou de modo a enfatizar as especificidades da dinâmica brasileira (Oliveira 2008; Boschetti 2018) - perde qualquer escrúpulo e assume explicitamente a sua real motivação, isto é, a superexploração à custa do extermínio dos pobres, negros e marginalizados (Santos et al. 2020; Santana 2021). No Brasil à deriva de Bolsonaro, onde não se assumiram medidas mínimas de proteção à vida e gestão da crise sanitária (Guimarães 2020), as mortes passaram a ser contabilizadas, literalmente, como lucros e dividendos. É dessa forma que a realidade coincide com a alegoria da barbárie de Bacurau e os traços xenófobos, fascistas e autoritários presentes nos clichês utilizados para definir o 
vilão Michael se presentificam em Bolsonaro, numa versão aclimatada ao tempo-espaço brasileiro. Esse atual estado político, somado ao acúmulo das mortes de milhares de pessoas, especialmente da população periférica e subalterna, se faz o país soluçar e lamentar "todo esse mundo tão mau" (Ricardo e Cardoso 1967), ${ }^{15}$ ainda não o faz equalizar, como acontece no longa, uma reação conjunta e estratégica diante de tantas perdas e ataques.

\section{Considerações finais}

As obras artísticas compromissadas, de certo, não resolvem questões sociais e políticas, cujas soluções dependem, efetivamente, da ação coletiva. No entanto, elas são essenciais, utilizando um termo corrente da atualidade, para nutrir o imaginário, diagnosticar os desafios, apontar caminhos alternativos e propor formas de práticas emergentes, especialmente em face do enorme aparato económico-midiático neoliberal de nossos tempos. É esse o caso dos filmes pertencentes à cena do cinema contemporâneo de Pernambuco, e em particular dos longas de Kleber Mendonça Filho, cuja matéria também é composta de escolhas estéticas e estratégias singulares. Se o diretor, centralmente partícipe do círculo de atuação da geração dos anos 2000 de Recife, assim como ela, ressignificou a tradição anticapitalista (de diferentes vertentes) legada do campo intelectual e cultural de Pernambuco a partir do que lhe é familiar, também o fez por meio de uma representação que reativou o passado em uma apropriação autoral do cinema de género.

Ao analisar as suas práticas, que envolvem todo um complexo de intenções e posicionamentos extraestéticos e formais a um só tempo, nota-se, no entanto, que elas não escapam dos paradoxos. Se por um lado demonstram um elevado grau de diagnóstico, bastante percetível nos filmes - fator que também corrobora para torná-los verdadeiros exemplos da potência da arte em detetar o que "fervilha" abaixo da superfície ou paira no ar da atmosfera social e ainda não tomou forma definida, como se buscou apontar na interpretação proposta em torno da política brasileira da última década - por outro, ao assumir uma

\footnotetext{
${ }^{15}$ Trecho da música Bicho da noite (Sérgio Ricardo, Joaquim Cardoso,1967) que inspirou o título de Bacurau.
}

aniki Ensaios | Essays 
perceção reflexa do "outro", ou seja, das classes subalternas, não conferindo assim força consequente à ação demandada, correm um alto risco de performá-la.

A evidente negação da privatização dos modos de vida, das desigualdades obscenas e da deterioração das relações humanas no atual estado de ser capitalista encontra em Kleber Mendonça Filho a defesa da democracia assentada no genuíno anseio de verem construídas no país as bases de uma comunidade política de direitos (cf. Mendes 2019), livre da sujeição dos arcaísmos autoritários que insistem em deslocar as vicissitudes do universo doméstico para o público. No entanto, a rebeldia das suas imagens, que projetam as vozes silenciadas dos escombros da história brasileira sem receio de enfrentar os próprios fantasmas, especialmente em $O$ som ao redor, parece imiscuída de uma perspetiva adiada de ação radical, de um suspense, presente em maior grau em Aquarius. Já em Bacurau, feito em parceria com Juliano Dornelles, a força política é adensada nos jogos de contradição manifestos nas escolhas estilísticas, mas enfraquece nos momentos em que esse trabalho com a ambiguidade é suprimido em favor da transparência e da grafia da linguagem hegemônica, como acontece na elevação do tom cómico-performático e exortativo do desfecho.

Talvez o limite do horizonte político das práticas de Kleber Mendonça Filho seja justamente a não superação das fronteiras da negação, já que contida em uma forma que torna opaca a força propositiva dos sujeitos em cujos ombros mais pesam as mazelas nacionais. Nesse enredo paradoxal, não deixam de refratar, em parte, o mesmo impasse para o qual anseiam uma solução: o de um país cuja população necessita correr o risco de se aventurar além do próprio quintal, do doméstico, da existência aprisionada ao privado, para, dessa maneira, se encontrar com a diferença, com o outro, o divergente, o público. Esta parece ser, afinal, a única maneira de se construir uma comunidade política efetivamente solidária e emancipada. 


\section{Referências}

Agamben, Giorgio. 2009. “O que é o contemporâneo?.” Em O que é o contemporâneo? E outros ensaios, traduzido por Vinícios $\mathrm{N}$. Honesco, 55-73. Chapecó: Argos.

Angelo, Tiago e Calegari, Luiza. 2021. "Fachin anula condenações de Lula e desloca processos para Brasília." Conjur, 8 de março de 2021. https://www.conjur.com.br/2021-mar-08/fachin-declaravara-curitiba-incompetente-julgar-lula.

Araujo, Inácio. 2019. "Réplica: críticos dizem que 'Bacurau' é um filme de propaganda; e daí?" Folha de S. Paulo, 16 de setembro de 2019. https://www1.folha.uol.com.br/ilustrada/2019/09/criticosdizem-que-bacurau-e-um-filme-de-propaganda-e-dai.shtml.

Araújo, Beatriz B. M. 2013. "Crítica de Kléber Mendonça Filho incomoda executivo da gigante Globo Filmes." Jornal do Commercio, 22 de fevereiro de 2018. https://jc.ne10.uol.com.br/canal/cultura/cinema/noticia/2013/ 02/22/critica-de-kleber-mendonca-filho-incomoda-executivoda-gigante-globo-filmes-74261.php.

Araújo, Luciana. 1997. A Crônica de cinema no Recife dos anos 50. Recife: Fundarpe.

Azerêdo, Genilda. 2020. "Kleber Mendonça e a ciranda de todos nós: Configurações espaciais e resistência." Significação: Revista de cultura audiovisual 47(53): 265-277. https://doi.org/10.11606/issn.2316-7114.sig.2020.148910.

Barros, Isabelle. 2017. "Jornalista e fotógrafa Ana Farache será nova gestora do cinema da Fundação." Diário de Pernambuco, 16 de janeiro de 2017. https://www.diariodepernambuco.com.br/noticia/viver/2017/0 1/jornalista-e-fotografa-ana-farache-sera-nova-gestora-docinema-da-fund.html.

Bentes, Ivana. 2019. "Bacurau e a síntese do Brasil brutal." Cult, 29 de agosto de 2019. https://revistacult.uol.com.br/home/bacuraukleber-mendonca-filho/.

Bernardet, Lucila. 1970. O cinema Pernambucano de 1922 à 1931: Primeira abordagem. Dissertação de mestrado. São Paulo: Universidade de São Paulo, Faculdade de Filosofia, Letras e Ciências Humanas. 
Boschetti, Ivanete. org. 2018. Expropriação e direitos no capitalismo. São Paulo: Cortez.

Bourdieu, Pierre. 1996. As regras da arte: Gênese e estrutura do campo literário. São Paulo: Companhia das Letras.

Cândido, Antônio. 1984. “A revolução de 1930 e a cultura.” Novos Estudos

Cebrap 2(4):

27-

36. https://edisciplinas.usp.br/pluginfile.php/4332357/mod res ource/content/1/ANTONIOCANDIDO Revolucaode30eaCultur a.pdf.

Cavalcante, Sávio. 2020. "Classe média e ameaça neofascista no Brasil de Bolsonaro." Crítica Marxista 50: 121-130. https://www.ifch.unicamp.br/criticamarxista/arquivos bibliote

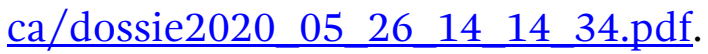

Costa, Mannuela R. 2017. Cinema Brasileiro independente no contexto contemporâneo: Entre a ficção e a realidade. Tese de doutorado. Rio de Janeiro: Programa de Pós-Graduação da Escola de Comunicação da Universidade Federal do Rio de Janeiro.

Cunha Filho, Paulo C. 2010. A utopia provinciana: Recife, cinema, melancolia. Recife, UFPE: Editora Universitária.

Falcão, Márcio e Vivas, Fernanda. 2021. "Cármen Lúcia muda voto, e $2^{\mathrm{a}}$ turma do STF declara que Moro foi parcial ao condenar Lula.” G1, 23 de março de 2021. https://g1.globo.com/politica/noticia/2021/03/23/carmenlucia-muda-voto-e-2a-turma-do-stf-declara-que-moro-foi-parcialao-condenar-lula.ghtml.

Fernandes, Eduarda. 2017. "Ministério Público abre inquérito contra cineasta Pernambucano Kleber Mendonça Filho." Diário de Pernambuco, 20 fevereiro de 2017. https://www.diariodepernambuco.com.br/noticia/viver/2017/0 2/mpf-inquerito-kleber-mendonca-filho.html.

Figueirôa, Alexandre. 2000. Cinema Pernambucano: Uma história em ciclos. Recife: Fundação de Cultura Cidade do Recife.

Folha de S. Paulo. 2012. “'O som ao redor’ é um dos 10 melhores filmes do ano, segundo o 'New York Times'." Folha de S. Paulo, 15 dezembro de 2012. https://m.folha.uol.com.br/ilustrada/2012/12/1202011-o-som- 
ao-redor-e-um-dos-dez-melhores-filmes-do-ano-segundo-o-newyork-times.shtml.

França, Andréa. 2003. Terras e fronteiras no cinema político contemporâneo. Rio de Janeiro: 7 Letras.

Genestreti, Guilherme. 2016. "Comissão brasileira do Oscar nega partidarização em escolha de indicação." Folha de S. Paulo, 19 agosto de 2016. https://www1.folha.uol.com.br/paywall/login.shtml?https://w ww1.folha.uol.com.br/ilustrada/2016/08/1804520-comissaobrasileira-do-oscar-nega-partidarizacao-em-escolha-deindicacao.shtml.

Guimarães, Cátia. 2020. “Covid-19: Especialistas falam sobre políticas de proteção social." Agência Fiocruz de Notícias, 27 de maio de 2020. https://agencia.fiocruz.br/covid-19-especialistas-falamsobre-politicas-de-protecao-social.

Harvey, David. 2020. “O 'novo' imperialismo: Acumulação por desposessão." Em Os sentidos do Mundo: Textos essenciais, traduzido por Artur Renzo, 281-311. São Paulo: Boitempo.

Hermsdorff, Renato. 2016. “Aquarius: 'Eu não tenho o menor interesse em fazer filmes «de arte»', diz diretor." Adoro Cinema, 2 de setembro de 2016 https://www.adorocinema.com/noticias/filmes/noticia$124170 /$.

Ikeda, Marcelo G. 2011. O modelo das leis de incentivo fiscal e as políticas públicas cinematográficas a partir da década de noventa. Dissertação de mestrado. Niterói: Universidade Federal Fluminense, Programa de Pós-Graduação em Comunicação.

Jameson, Fredric. 1997. “A lógica cultural do capitalismo tardio.” Em: Pós-modernismo: A lógica cultural do capitalismo tardio, traduzido por Maria Elisa Cevasco, 27-79. São Paulo: Editora Ática.

\section{1.} . 2021. "Estética hoje." Zero à esquerda, 11 fevereiro de

https://zeroaesquerda.com.br/index.php/2021/02/11/esteticahoje-fredric-jameson.

Jansen, Roberta. 2016. “Houve retaliação a 'Aquarius', diz Kleber Mendonça Filho Sobre Oscar.” G1, 20 de setembro de 2016. 
http://g1.globo.com/pop-arte/cinema/noticia/2016/09/houveretaliacao-aquarius-diz-kleber-mendonca-filho-sobre-oscar.html.

Kliass, Paulo. 2021. "Brasil mergulha no fosso da desigualdade." Outras palavras, 15 de junho de 2021. https://outraspalavras.net/desigualdades-mundo/brasilmergulha-no-fosso-da-desigualdade/.

Marques, Mariana R. s.d. "O que podemos esperar de Bacurau, filme de Kleber Mendonça Filho e Juliano Dornelles?” Instituto de cinema. https://institutodecinema.com.br/mais/conteudo/o-quepodemos-esperar-de-bacurau-filme-de-kleber-mendonca-filho-ejuliano-dornelles.

Marson, Melina I. 2009. Cinema e políticas de Estado: Da Embrafilme à Ancine. São Paulo: Escrituras Editora.

Martuscelli, Danilo E. 2020. "Polêmicas sobre a definição do Impeachment de Dilma Rousseff como Golpe de Estado." Revista de Estudos e Pesquisas sobre as Américas 14(2): 67-102. https://periodicos.unb.br/index.php/repam/article/view/28759

Melo, Patricia Bandeira e Galiza, Cleide. 2014. "Alta intervenção estatal: O caso do Brasil, da Argentina e da França." Em O Financiamento do cinema: Os níveis de intervenção estatal na produção mundial, 49-119. Recife: Fundação Joaquim Nabuco, Editora Massangana.

Mena, Fernanda. 2013. "No quintal de Kleber Mendonça Filho." Folha de S. Paulo, 7 de fevereiro de 2013. https://m.folha.uol.com.br/ilustrissima/2013/02/1231445-noquintal-de-kleber-mendonca-filho.shtml.

Mendes, Vinícius. 2019. "Não há como dialogar com Bolsonaro: Entrevista a Kleber Mendonça Filho." Le monde diplomatique Brasil, 2 de setembro de 2019. https://diplomatique.org.br/naoha-como-dialogar-com-bolsonaro/.

Mendonça Filho, Kleber. 2018. "Uma carta aberta ao Ministro da Cultura Sr. Sergio Sá Leitão e à sociedade". Facebook, 29 de maio de 2018. https://www.facebook.com/OSomAoRedor/posts/2030550990 350852/.

. 2020. "Bacurau teve um orçamento de 8 milhões de $\mathrm{R} \$$. Filmamos 8 semanas e meia, todos foram pagos, a comida era 
excelente, todo mundo se respeitou e trabalhou bem. Com um milhão a mais para filmar, teria sido muito melhor e menos sofrido. Mas não tenho o que reclamar." Twitter. 09 de maio de 2020.

https://twitter.com/kmendoncafilho/status/1259282473738997 766? lang=bg.

Miceli, Sergio. 1979. Intelectuais e classe dirigente no Brasil (1920-1945). São Paulo: Difel.

Milão, Diego A. P. 2019. "O tempo que vem e o campo que há no sertão de Bacurau." Le monde diplomatique, 10 de agosto de 2019. https://diplomatique.org.br/o-tempo-que-vem-e-o-campo-queha-no-sertao-de-bacurau/.

Musse, Ricardo. 2019. "Sobre Bacurau". A terra é redonda, 6 de outubro de 2019. https://aterraeredonda.com.br/sobre-bacurau/.

Nagib, Lucia. 2002. O cinema da Retomada: Depoimentos de 90 cineastas dos anos 90. São Paulo: Ed. 34.

. 2006. A utopia no cinema brasileiro. São Paulo: Cosac Naify.

Napolitano, Marcos e Vilaça, Mariana M. 1998. “As relíquias do Brasil em debate." Revista brasileira de História 18 (35): 53-75. https://doi.org/10.1590/S0102-01881998000100003.

Nascimento, Débora e Veras, Luciana. 2019. "Fiz o contrário do que se esperava”. Continente, 2 de setembro de 2019. https://revistacontinente.com.br/edicoes/225/rfiz-0-contrariodo-que-se-esperavar--2.

Nogueira, Amanda M. C. 2014. A brodagem no cinema Pernambucano. Tese de doutorado. Recife: Universidade Federal de Pernambuco, CAC - Departamento de Comunicação.

2009. O novo ciclo de cinema em Pernambuco: A questão do estilo. Dissertação de mestrado. Recife: Universidade Federal de Pernambuco, CAC - Departamento de Comunicação.

Nogueira, Amanda M. Custódio e Cunha Filho, Paulo Carneiro da, org. 2016. A aventura do Baile Perfumado: 20 anos depois. Recife: CEPE.

Nogueira, Amanda e Pessoa, Gabriela Sá. 2016. "Em nova polêmica, 'Aquarius' recebe classificação indicativa 18 anos." Folha de S. 
Paulo, 23 de agosto de 2016. https://www1.folha.uol.com.br/ilustrada/2016/08/1806117em-nova-polemica-aquarius-recebe-classificacao-indicativa-de18-anos.shtml.

Oliveira, Francisco de. 2008. Critica da razão dualista; O ornitorrinco. São Paulo: Boitempo.

Oliveira, Maria Carolina V. 2014. "Novíssimo" cinema brasileiro: Práticas, representações e circuitos de independência. Tese de doutorado. São Paulo: Universidade de São Paulo, Faculdade de Filosofia, Letras e Ciências Humanas - Programa de PósGraduação em Sociologia.

Oricchio, Luiz F. Zanin. 2003. Cinema de novo: Um balanço crítico da Retomada. São Paulo: Estação Liberdade.

Ortiz, Renato. 2006. A moderna tradição brasileira. São Paulo: Brasiliense.

Paiva, Samuel. 2008. "Do curta ao longa: Relações estéticas no cinema contemporâneo de Pernambuco." Em: Estudos de cinema SOCINE, organizado por Esther Hamburger, Gustavo Souza, Leandro Mendonça e Tunico Amancio, 99-106. São Paulo: Annablume, Fapesp.

Pellegrini, Tânia. 2008. Despropósitos: Estudos de ficção brasileira contemporânea. São Paulo: Annablume/ Fapesp.

Pinto, Ivonete. 2012. "Cinema irrelevante: Uma análise do cinema nacional a partir das percepções de Jean- Claude Bernardet." Abraccine, 7 de abril de 2021. https://abraccine.org/2013/06/18/cinema-irrelevante-umaanalise-do-cinema-nacional-a-partir-das-percepcoes-de-jeanclaude-bernardet/.

Prysthon, Ângela F. 2017. "Paisagens em desaparição. Cinema de Pernambuco e a relação com o espaço.” E-Compós: Revista da Associação Nacional dos Programas de Pós-Graduação em Comunicação 20(1): 1-17. https://www.e-compos.org.br/ecompos/article/view/1348/919.

Rabello, Ivone D. 2015. "O som ao redor: Sem futuro, só revanche?.”, Novos Estudos - CEBRAP 00(101): 157-173. https://doi.org/10.1590/S0101-33002015000100009. 
Ramos, Fernão P. 2002. "Má-consciência, crueldade e 'Narcisismo às avessas' no cinema brasileiro contemporâneo." Comunicação \& informação. 5(1/2): 13-24.

Ridenti, Marcelo. 2010. Brasilidade revolucionária: Um século de cultura e política. São Paulo: Editora UNESP.

. 2014. "Caleidoscópio da cultura brasileira (1964-2000)." Em: Cultura e sociedade: Brasil e Argentina, organizado por Sergio Miceli e Heloisa Pontes, 21-71. São Paulo: Edusp.

- 2018. "Mudanças culturais e simbólicas que abalam o Brasil.” Plural: Revista do programa de pós-graduação em Sociologia da USP 25(1): 45-62. https://doi.org/10.11606/issn.21768099.pcso.2018.149012.

Rivetti, Ugo. 2020. "Cultura e política em tempos de crise.” Resgate Revista interdisciplinar de cultura 28(00): 1-21. https://doi.org/10.20396/resgate.v28i0.8658298.

Rosa, João Guimarães. 2001. Primeiras estórias. $15^{\mathrm{a}}$ ed. Rio de Janeiro: Nova Fronteira.

Rossini, Miriam de S. 2007. "O corpo da nação: Imagens e imaginários no cinema brasileiro.” Revista Famecos (34): 22-28.

Santana, Bianca. 2021. "Covid-19 e a população negra brasileira." EcoaUOL, 2 de fevereiro de 2021. https://www.uol.com.br/ecoa/colunas/biancasantana/2021/02/02/covid-19-e-a-populacao-negrabrasileira.htm.

Santos, Márcia P. Alves dos; Nery, Joilda Silva; Goes, Emanuelle Freitas; Silva, Alexandre da; Santos, Andreia B. Silva dos; Batista, Luís Eduardo; Araújo, Edna Maria de. 2020. "População negra e Covid19: Reflexões sobre racismo e saúde." Estudos avançados 34 (99): 225-243. Acessado em 22 de Setembro de 2021. https://doi.org/10.1590/s0103-4014.2020.3499.014.

Santos, Márcia V. M. 2019. O cinema contemporâneo de Pernambuco. Tese de doutorado. São Paulo: Universidade de São Paulo, Faculdade de Filosofia, Letras e Ciências Humanas - Programa de Pós-Graduação em Sociologia. 
Saraiva, Leandro. 2013. Da estética da fome à estética do lixo, da alegoria da esperança à do desengano. Retrato do Brasil. Belo Horizonte: Editora manifesto.

Schwarz, Roberto. 1978. “Cultura e política, 1964-69.” Em: O pai de família e Outros estudos, editado por Antônio Cândido e Antonio Callado, 61-92. Rio de Janeiro: Paz e Terra.

Teixeira Neto, Wanderley de Mattos. 2018. "Kleber Mendonça Filho, 'O som ao redor' e a construção de uma ideia sobre o cinema Pernambucano." Aniki: Revista Portuguesa da Imagem em Movimento 5(2): 420-436. Acessado em 15 de Agosto de 2021. https://doi.org/10.14591/aniki.v5n2.398.

Williams, Raymond. 2005. "Base e superestrutura na teoria cultural marxista." Revista da USP (66): 209224. https://doi.org/10.11606/issn.2316-9036.v0i66p209-224. . 2007. "Os usos da teoria da cultura." Em: Margem esquerda $n^{\circ}$ 9, editado por Ivana Jinkings e João A. Peschanski, 179-196. São Paulo: Boitempo Editorial.

Xavier, Ismail. 2006. "Corrosão social, pragmatismo e ressentimento: Vozes dissonantes no cinema brasileiro de resultados." Novos estudos - CEBRAP (75): 139-155.

. 2021. "O som ao redor: Arqueologia do vertical moderno no Recife." Galáxia 46(46): 1-17. Acessado em 15 de Agosto de 2021. http://dx.doi.org/10.1590/1982-2553202152911.

\section{Filmografia}

A História da Eternidade [longa-metragem, 35mm]. Dir. Camilo Cavalcante. Aurora Cinema, república Pureza Filmes, ArtHouse, Brasil, 2015. 120 min.

Aquarius [longa-metragem, digital]. Dir. Kleber Mendonça Filho. Cinemascópio Produções, SBS, Videofilmes, Globo Filmes, Vitrine Filmes, Brasil, 2016. 142 min.

Amarelo Manga [longa-metragem, 35mm]. Dir. Cláudio Assis. Olhos de Cão, Parabólica Brasil, RioFilme, Brasil, 2003. 101 min. 
Amigos de Risco [longa-metragem, digital]. Dir. Daniel Bandeira. Símio Filmes, CinemaScópio, Cátia Oliveira, Daniel Bandeira, Juliano Dornelles, Sarah Hazin, Brasil, 2007. 88 min.

Bacurau [longa-metragem, digital]. Dir. Kleber Mendonça Filho. SBS, Vitrine Filmes, Brasil, 2019. $131 \mathrm{~min}$.

Baile Perfumado [longa-metragem, 35mm]. Dir. Lírio Ferreira e Paulo Caldas. Saci Filmes, RioFilme, Brasil, 1997. 93 min.

Cinema, Aspirinas e Urubus [longa-metragem, 35mm]. Dir. Marcelo Gomes. REC Produtores Associados, Dezenove Som e Imagens, Imovision, Brasil, 2005. $99 \mathrm{~min}$.

Crítico [longa-metragem, digital]. Dir. Kleber Mendonça Filho. Cinemascópio Produções, Vitrine Filmes, Brasil, 2008. 75 min.

Eles Voltam [longa-metragem, digital]. Dir. Marcello Lordello. Trincheira Filmes, Plano 9 Produções, Vitrine Filmes, Brasil, 2014. $100 \mathrm{~min}$.

Eletrodoméstica [curta-metragem, digital]. Dir. Kleber Mendonça Filho. Cinemascópio Filmes, Brasil, 2005. 22 min.

Pacific [longa-metragem, digital]. Dir. Marcelo Pedroso. Símio Filmes, Vitrine Filmes, Brasil, 2009. 73 min.

Um lugar ao sol [longa-metragem, digital]. Dir. Gabriel Mascaro. Símio Filmes, Vitrine Filmes, Brasil, 2009. 66 min.

Recife Frio [curta-metragem, digital]. Dir. Kleber Mendonça Filho. Cinemascópio Filmes, Brasil, 2009. 24 min.

Tatuagem [longa-metragem, digital]. Dir. Hilton Lacerda. Imovision, Brasil, 2013. $120 \mathrm{~min}$.

\section{Sound and Fury in Brazilian Cinema: Culture and politics viewed from Pernambuco}

ABSTRACT This essay highlights the political allegiances of Kleber Mendonça Filho's cinema by examining his three feature films: Neighboring Sounds (2012), Aquarius (2016) and Bacurau (2019). It points out the characteristics of his work's encounters and disagreements with the Brazilian socio-historical reality, especially in the last decade, a period marked by mass protests in 2013, the overthrow of President Dilma Rousseff (2016) and the election of Jair Bolsonaro (2018). To accomplish this goal, it

aniki Ensaios | Essays 
situates Kleber Mendonça as part of Pernambuco's contemporary cinema scene and proposes an analytical method that simultaneously articulates aesthetic and extraaesthetic factors. It concludes that this film triad, despite being made up of paradoxical forms of practice, offers an important opportunity to think about Brazil, its recent history and the extant relations between culture, politics and society.

KE YW OR DS Cinema; culture; politics; Pernambuco; Kleber Mendonça Filho.

Recebido a 23-06-2021. Aceite para publicação a 25-09-2021.

aniki Ensaios | Essays 